\title{
In The Name Of Allah, the Beneficent the Merciful Designing a Low Cost Device to Save the Corrupted Electricity
}

\author{
Md. Mizanur Rahman ${ }^{1,}$ Md. Aminul Islam ${ }^{2}$, Asraful Haque Ronee ${ }^{3}$, \\ Md. Ashraful Huq ${ }^{4}$, Dhin Mohammed Parvez ${ }^{5}$ \\ 1, 2.3, 5 Department of EEE, University of Asia Pacific, Dhaka, Bangladesh \\ ${ }^{4}$ Department of EEE, Ahsanullah University of Science and Technology (AUST)
}

\begin{abstract}
Modernization of energy meter is needed to protect the corruption of electricity. Low cost device is added with energy meter will help to save the large amount of corrupted electricity. The paper aims to show that how electricity is disconnected from the main supply to load after detecting electricity theft in energy meter.

Keywords: Microcontroller ATMEGA 8, 5 Volt Relay, Meter tampering
\end{abstract}

\section{Introduction}

Electricity is an essential element for development of society but electricity theft is a curse for society. The amount of generated electricity is decreases for transmission and distribution losses which causes financial damage. If theft of electricity occurs rapidly then the backbone of economics is also broken able. There are some energy meter (analog and digital) which show the amount of consumed electricity but not detect the tempering and electricity theft. Already we had known about such an energy meter which can detect the tempering and electricity theft in "Design and Implementation of a Novel Protection Device to Prevent Tampering and Electricity Theft in Commercial Energy Meters" which published at volume 01, issue 01, in International Journal of Computer and Information Technology (IJCIT) on July 2010, by Himadri Shekhar Dey, Munzur-ul-mamun, Mohammad Shahabad,Arman Ahamed, Shalah Uddin Ahamed and Kazi Shamsul Arefin. They show in their paper that their propose device detect the tempering and electricity theft in commercial energy meter but cannot stop the supply of electricity to load after tempering and electricity theft in commercial energy meter. There are some problems in their proposed device. In this paper we solution of those problem and design a system in which the electricity is not going to load after tampering and electricity theft in commercial energy meter which saves the large amount of corrupted electricity

\subsection{SHORTING THE PHASE CURRENT COIL}

\section{Different Types Of Tampering In An Analog Meter}

When the current coil is shorted by the consumer then the phase current goes through the short and reading of current coil is zero, $\mathrm{I}=0$. We know that $\mathrm{P}=\mathrm{VI}$. If $\mathrm{I}=0$ then the power $\mathrm{P}=0$. This arrangement of analog meter can not show the amount of power consumption in the display [6]. There is no current flow through the CTs when the load is in off mode.The disc does not rotate because of no resultrant flux.The microcontroller does not find any voltage change and so puts on the red light. Althogh there is no electricity thefting but the device show that it detect successfully. This is one of the laggings of this design.

\subsection{REVERSING THE DIRECTION OF CURRENT FLOW}

To exchange the side between load and supply the energy meter does not show any rating. It acts as there is no load connected in the energy meter.

\subsection{DISCONNECTING THE NUTRAL LINE}

In fig 1 show that neutral line connected to CT .If neutral line is disconnected the potential transformer does not read the voltage difference as well as $\mathrm{V}$, then $\mathrm{V}=0$ [6]. We know that $\mathrm{P}=\mathrm{VI}$. Then $\mathrm{P}=0$ and display not show any amount of consumption electricity.

\subsection{TAMPERING BY USING MAGNET}

Aluminum disk can stopped and rotate slowly if a magnet is used ,because magnet restrict the flux produced by the device due to current flow which is help to rotate the aluminum disk. So, by using magnet electricity theft can be done [6]. The design already gives a solution about stop the disc . But what is happened under slow rotating condition. The device can only detect when never find any voltage change. But during slow rotating voltage will be changed slowly. And we can see that microcontroller can not detect slow change in voltage. So this is another laggings of this implementation 


\section{Tampering In A Digital Meter}

In the digital meter IP and IN are both measured .At normal condition both IP and IN are equal value. The current from CT and phase voltage from PT are provided to the microprocessor unit. The microprocessor calculates the amounts of energy consumed and display the LCD. IP and IN are compared in the microprocessor unit .If microprocessor unit found any difference then this digital meter detect the pilferage. It is experimentally found that the digital meter is not able to detect the pilferage when neutral is deliberately disconnected to tamper the meter. [6]

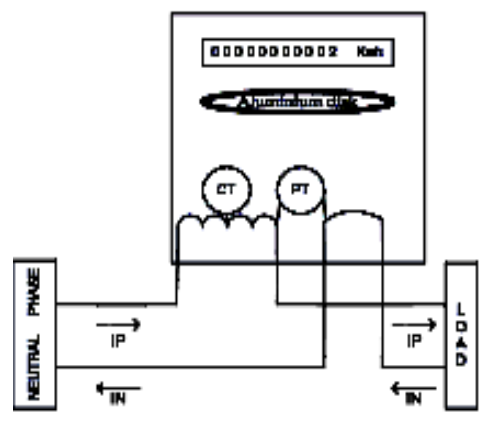

Fig 1.Analog Energy Meter

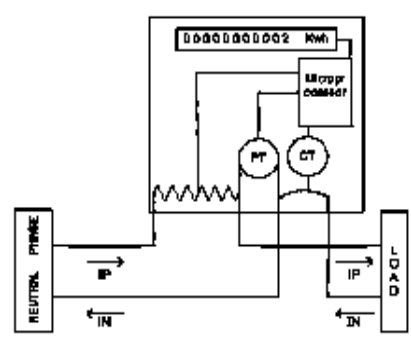

Fig 2.Digital Energy Mete

\section{The Proposed System}

This is a microcontroller based electrical system.

4.1 ELECTRONIC AND ELECTRICAL MATERIAL

In our proposed system we need an energy meter, a Microcontroller ATMEGA 8 and 5 volt Relay.

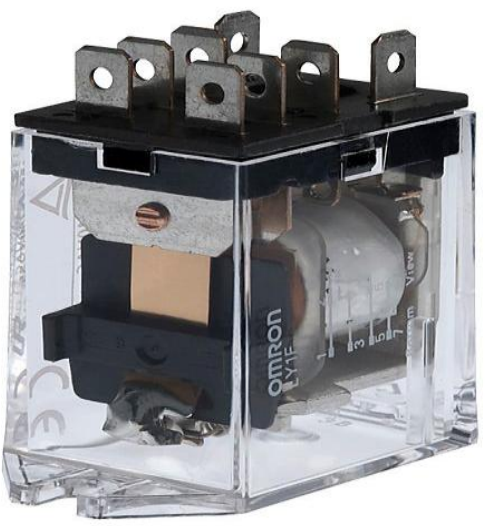

Fig 3. 5v Relay

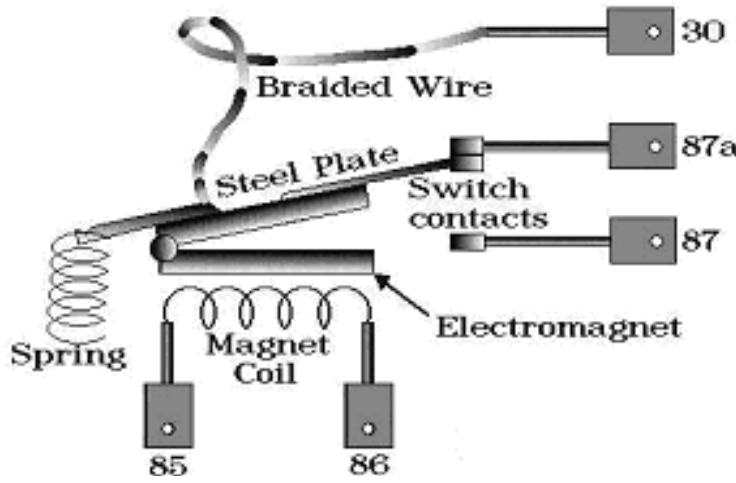

Fig. 4. Relay Switching System

\subsection{THE ATMEGA8 MICROCONTROLLER}

A microcontroller often serves as the "brain" of a mechatronic system. Like a mini, self-contained computer, it can be programmed to interact with both the hardware of the system and the user. Even the most basic microcontroller can perform simple math operations, control digital outputs, and monitor digital inputs. Most modern controllers have analog-to-digital converters, high-speed timers and counters; interrupt capabilities, outputs that can be pulse-width modulated, serial communication ports, etc. ATMEGA8 is one of the most popular microcontrollers used specially in automotive, industrial appliances and consumer applications. High-performance, Low-power Atmel AVR 8-bit Microcontroller. The low-power Atmel 8-bit AVR RISC-based microcontroller combines $8 \mathrm{~KB}$ of programmable flash memory, 1KB of SRAM, 512K EEPROM, and a 6 or 8 channel 10-bit A/D converter. The device supports throughput of $16 \mathrm{MIPS}$ at $16 \mathrm{MHz}$ and operates between 2.7-5.5 volts.

Some Key Parameters are given below
Parameter
Value
Flash (Kbytes)
8 Kbytes 
Pin Count

Max. Operating Frequency

CPU

No of Touch Channels

Hardware QTouch Acquisition

Max I/O Pins

Ext Interrupts

USB Transceiver

Quadrature Decoder Channels
32

$16 \mathrm{MHz}$

8-bit AVR

12

No

23

2

0

0

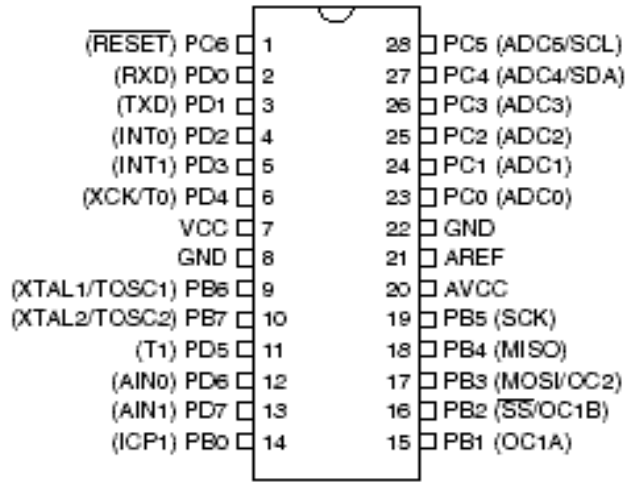

Fig 5. .ATmega8 Pin-out Diagram

\subsection{MODIFICATION OF DISK}

Now the disk represents itself with a small hole. The IR transmitter stands over the disk and IR receiver Stands below the disk. When infrared ray pass through the hole from transmitter to receiver then the output of IR receiver is $0 v$.The output of IR receiver with respect to disk speed is given below.

\begin{tabular}{|l|l|}
\hline Speed & \multicolumn{2}{|c|}{ Output of IR Receiver } \\
\hline No Rotation & - \\
\hline No Rotation & \\
\hline ow & \\
\hline Normal & \\
\hline
\end{tabular}

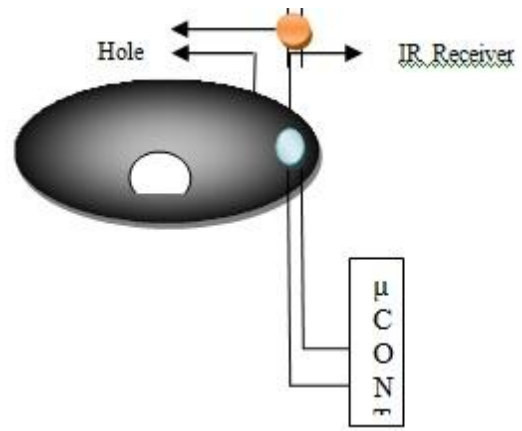

Fig 6: Proposed Aluminum Disk

V.

Working Procedure



Fig 7: Proposed Device

There are two CT (current transformer): CT1 and CT2. CT1 is connected to the phase line and CT2 is connected to the neutral line .IP is measured by the CT1 and IN is measured by CT2 respectively .IP and IN act as ADC (Analog to Digital Conversion) input of the microcontroller. If there are found any difference between IP and IN then microcontroller open the relay which is help to disconnect the main supply to load. In this system an IR sensor (transmitter and receiver) are used to protect the magnetically tampering. We consider a hole in 
rotating disc of analog meter. The output of IR receiver is varied with the speed of the rotating disk.The output of IR receiver is ADC (Analog to Digital Conversion) input of microcontroller. The output of IR receiver is not match the normal mode of rotating disk then microcontroller opens the relay which is help to disconnect the main supply to load. If load is in off mode (IP $=0$ ) the output of IR receiver is not match the normal mode of rotating disk then microcontroller does not opens the relay. At normal condition green light is on and at abnormal condition red light is on. Programme is needed to operate microcontroller. Software flow chart is given below:

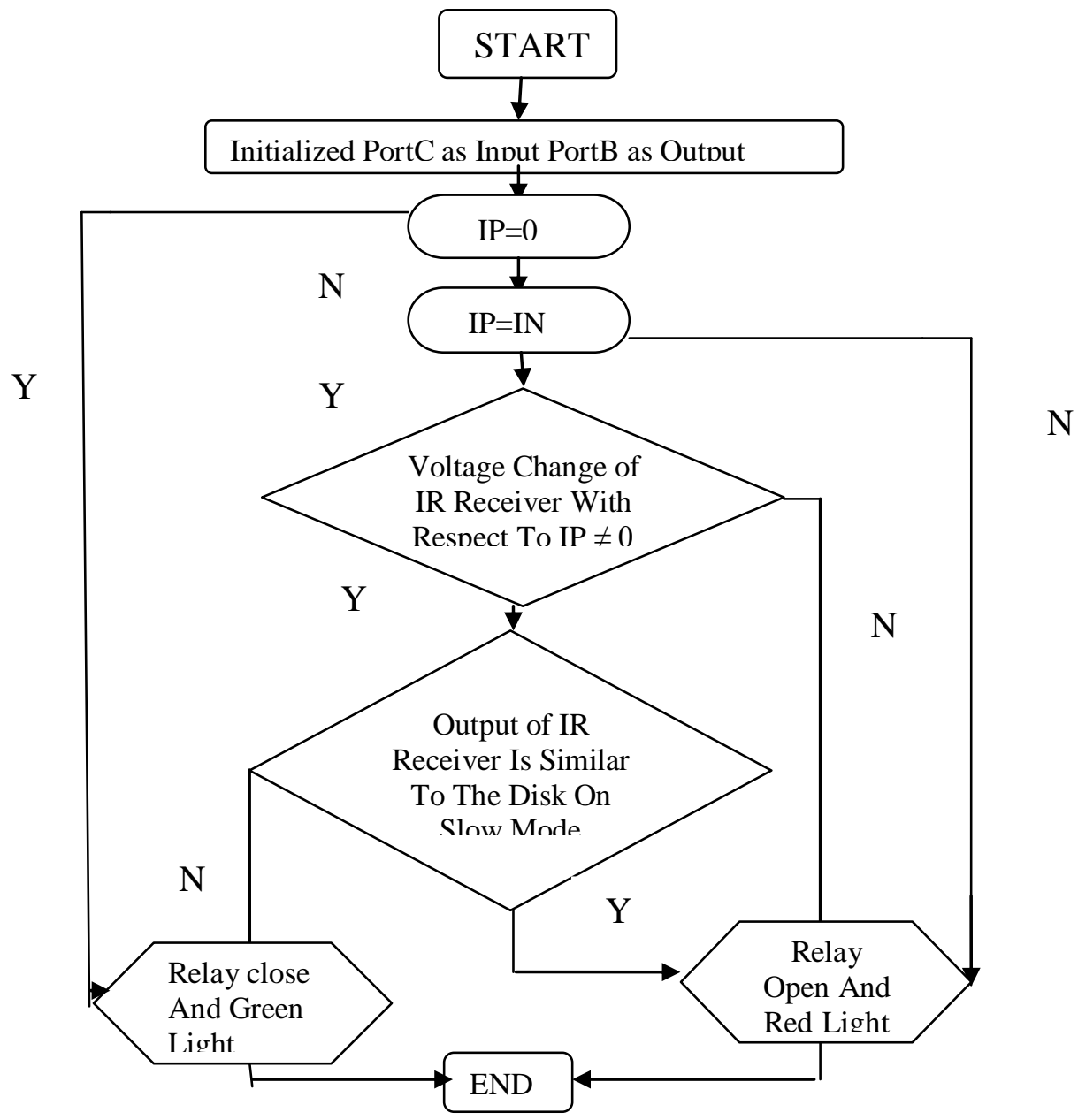

Fig 8: Flow chart of software

\section{Discussion}

An essential precondition for industrial development is uninterrupted supply of energy. Although the installed capacity for generation of electricity in the country is 2908 megawatt, the actual production does not exceed 2160 megawatt as against the peak demand of 2200 megawatt. The average level of system loss is still as high as $33.3 \%$. The demand for power will increase by $300 \mathrm{MW}$ annually and an investment of about Tk 110 billion up to the turn of the century will be needed to meet it [3].According to another study conducted by Transparency International Bangladesh (TIB) study in April 2005, in a household survey almost 4.3 percent households pay for tampering their meter [4], [5]. So, it is quite clear about the adverse effect electricity thefts like meter tampering have on economy of the country. The device designed in this paper may be a useful option to overcome this problem. By using this device there are no chances to get electricity supply after meter tampering. So it is very helpful for government to reduce the system loss in power sector

\section{Conclusion}

In this paper we design a low cost microcontroller based device. The proposed device is a modified device .we hope that this device also identified, protect the tempering of energy meter and save the large amount of corrupted electricity which is very helpful to make strong economic of a country. 


\section{REFERENCES}

[1] http://www.futurlec.com

[2] http://www.atmel.com

[3] http://Bangladesh Energy.htm

[4] Transparency International Bangladesh (TIB), "Corruption in Bangladesh: A household survey," Available at http:www.tibangladesh.org/documents/HouseholdSurvey 200405-sum.pdf, April 20, 2005, Accessed on 26 June, 2010.

[5] United States Agency for International Development (USAID), "Integrity in Bangladesh's rural electrification," April, 2006.

[6] Himadri Shekhar Dey, Munzur-ul-Mamun, Mohammed shahadat, Arman Ahamed, Shalah UddinAhamed, and Kazi Shamsul Arefin," Design and Implementation of a NovelProtection Device to Prevent Tampering andElectricity Theft in Commercial Energy Meters” ,International Journal of Computer and Information Technology (IJCIT), Volume 01, Issue 01, pp.88-94

[7] Subrata karmoker, Kazi Shamsul Arefin and A. S. Zaforullah Momtaz "Controlling Water Pump Machine Using Cellular Mobile Telephony", International Journal of Computer and Information Technology (IJCIT), Volume 02, Issue 01, pp.84-88

\section{AUTHORS}

Md. Mizanur Rahman. B.Sc. in EEE .University of Asia Pacific House No.73, Road No.5A, Dhanmondi , Dhaka,1209, Bangladesh.

Md. Aminul Islam. Now he is studying in EEE department (4th year 1st semester), University of Asia Pacific (UAP) House No.73, Road No.5A, Dhanmondi, Dhaka1209, Bangladesh

Asraful Haque Ronee. B.Sc. in EEE .University of Asia Pacific House No.73, Road No.5A, Dhanmondi Dhaka. Bangladesh.

Md. Ashraful Huq B.Sc. in EEE,,Ahsanullah University Of Science And Technology (AUST). 141-142 Love Road, Tejgaon, Dhaka. Bangladesh

Dhin Mohammed Parvez. Now he is studying in EEE department (4th year 1st semester), University of Asia Pacific (UAP),House No.73, Road No.5A, Dhanmondi, Dhaka1209, Bangladesh 